\title{
Effects of soaking and germination conditions on gamma - aminobutyric acid and total phenolic content in geminated mung bean
}

\author{
Anh T. Vu*, Tuyen C. Kha, \& Huan T. Phan
}

Faculty of Food Science and Technology, Nong Lam University, Ho Chi Minh City, Vietnam

\author{
ARTICLE INFO \\ Research Paper \\ Received: May 24, 2018 \\ Revised: September 28, 2018 \\ Accepted: October 09, 2018

\section{Keywords} \\ Gamma - aminobutyric acid (GABA) \\ Germinated mung bean \\ Polyphenol \\ Temperature \\ Time
}

\section{* Corresponding author}

Vu Thuy Anh

Email: vuthuyanh@hcmuaf.edu.vn

\section{ABSTRACT}

Germinated mung bean is a well-known food due to its high content of gamma aminobutyric acid (GABA). This study was designed to test the effectiveness of soaking and germination conditions on GABA and total phenolic contents in germinated mung bean. The results showed that reasonable conditions for soaking mung bean was at $30^{\circ} \mathrm{C}$ within $8 \mathrm{~h}$, which created the highest content of GABA $(4,51 \mathrm{mg} / \mathrm{g})$. Meanwhile, the highest content of polyphenol $(1,25 \mathrm{mg} \mathrm{GAE} / \mathrm{g})$ was reached at $35^{\circ} \mathrm{C}$ within $8 \mathrm{~h}$. The optimized conditions for germinating mung bean were at $35^{0} \mathrm{C}$ for $24 \mathrm{~h}$ giving the most highest content for both GABA and TPC, 4,46 mg/g and 1,30 mg GAE/g, respectively.

Cited as: Vu, A. T., Kha, T. C., \& Phan, H. T. (2019). Effects of soaking and germination conditions on gamma - aminobutyric acid and total phenolic content in geminated mung bean. The Journal of Agriculture and Development 18(2), 112-118. 


\title{
Ảnh hưởng của điều kiện ngâm và ủ đến hàm lượng gamma - aminobutyric acid và polyphenol trong hạt đậu xanh nẩy mầm
}

\author{
Vũ Thùy Anh*, Kha Chấn Tuyền \& Phan Tại Huân
}

Khoa Công Nghệ Thực Phẩm, Trường Đại Học Nông Lâm TP. Hồ Chí Minh, TP. Hồ Chí Minh

\section{THÔNG TIN BÀI BÁO}

Bài báo khoa học

Ngày nhận: 24/05/2018

Ngày chỉnh sửa: 28/09/2018

Ngày chấp nhận: 09/10/2018

\section{Từ khóa}

Gamma - aminobutyric acid (GABA)

Hạt đậu xanh nẩy mầm

Nhiệt độ

Polyphenol

Thời gian

\section{*Tác giả liên hệ}

Vũ Thùy Anh

Email: vuthuyanh@hcmuaf.edu.vn

\section{TÓM TẮT}

Hạt đậu xanh nẩy mầm được biết đến như nguồn thực phẩm giàu các hợp chất sinh học như gamma aminobutyric acid và polyphenol. Nghiên cứu này thực hiện nhằm đánh giá tác động của điều kiện ngâm và ủ đến hàm lượng gamma - aminobutyric acid $(\mathrm{GABA})$ và polyphenol trong mầm hạt đậu xanh. Kết quả đạt được điều kiện ngâm hạt ở $30^{\circ} \mathrm{C}$ trong vòng 8 giờ cho hàm lượng GABA cao nhất $(4,51 \mathrm{mg} / \mathrm{g})$. Trong khi đó, hàm lượng polyphenol tổng cao nhất $(1,25 \mathrm{mg} \mathrm{GAE} / \mathrm{g})$ đạt được khi ngâm ở $35^{\circ} \mathrm{C}$ trong 8 giờ. Điều kiện ủ hạt ở $35^{\circ} \mathrm{C}$ trong vòng 24 giờ cho thấy hàm lượng GABA và polyphenol đều đạt giá trị cao nhất, lần lượt tương ứng với $4,46 \mathrm{mg} / \mathrm{g}$ và $1,30 \mathrm{mg} \mathrm{GAE} / \mathrm{g}$.

\section{1. Đặt Vấn Đề}

Đậu xanh (Vigna radiata L.; Họ: Fabaceae) tiếng Anh được gọi là green bean hoặc mung bean. Hạt đậu xanh chứa nhiều thành phần dinh dưỡng cân đối bao gồm protein và chất xơ cùng một lượng đáng kể các hợp chất sinh học. Hàm lượng protein, amino acid, oligosaccharide và polyphenol trong đậu xanh làm cho chúng có tính chống oxy hóa, kháng khuẩn, chống sưng tấy, giảm viêm và điều hòa chuyển hóa lipid. Trong suốt quá trình nẩy mầm hạt, các enzyme nội bào được hoạt hoá và các hợp chất dự trữ như protein và carbohydrate được phân cắt thành các phân tử nhỏ, đồng thời các hợp chất mới được hình thành. Cụ thể, quá trình nẩy mầm đã nâng cao hàm lượng Gamma - aminobutyric acid và polyphenol trong các hạt ngũ cốc (Paucar-Menacho \& ctv., 2017). Hàm lượng các hợp chất sinh học này có trong các mầm hạt ngũ cốc đã được chứng minh là có lợi ích đáng kể cho cơ thể con người (Randhir \& ctv., 2004). Theo tác giả Kanatt \& ctv. (2001), các hợp chất sinh học như GABA và polyphenol có hiệu quả sinh học rất cao như chống oxy hoá, kháng khuẩn, chống viêm nhiễm và chống sự tăng trưởng của các khối u. Như vậy, quá trình nẩy mầm cải thiện chất lượng dinh dưỡng và $\mathrm{y}$ học của đậu xanh (El-Adawy \& ctv., 2003).

Gamma - aminobutyric acid (GABA) là amino acid bốn carbon non-protein được biết đến như một chất ức chế dẫn truyền xung động thần kinh trong não và tủy sống của các loại động vật có vú. GABA được sản xuất chủ yếu từ một - decarboxyl hóa glutamate được xúc tác bởi glutamate decarboxylase $(\mathrm{GAD})$ và là chất làm giảm hội chứng mãn kinh, tăng cường miễn dịch, điều trị ung thư, ngăn ngừa các triệu chứng liên quan đến rượu và chống béo phì. Mặc dù GABA có sã̃n trong nhiều trái cây và rau quả, nồng độ của nó trong các loại thực phẩm tự nhiên rất thấp, dao động từ 0,03 
đến $2,00 \mu \mathrm{mol} / \mathrm{g}$ trọng lượng tươi. Nhiều nghiên cứu tập trung vào việc tìm kiếm những phương pháp mới để tăng hàm lượng GABA trong thực phẩm tự nhiên có thể có lợi cho sức khỏe con người (Song \& Yu, 2018).

Polyphenol là một họ các hợp chất tự nhiên, là các chất chuyển hóa thứ cấp và là các dẫn xuất của các phân tử pentose phosphate, shikimate và phenylpropanoid trong thực vật. Các hợp chất phenolic thể hiện một loạt các đặc tính có lợi cho sức khỏe như: chống dị ứng, chống viêm, chống vi khuẩn, chống oxy hóa, chống huyết khối, bảo vệ tim mạch và các tác dụng giãn mạch. Một số tác dụng có lợi từ các hợp chất phenolic chủ yếu là do hoạt tính chống oxy hóa của chúng. Các lợi ích sức khỏe liên quan đến polyphenol và ứng dụng của chúng đã được đề cập đến trong nhiều nghiên cứu (Ajila \& ctv., 2011).

Nhìn chung, các nghiên cứu cho thấy hạt nảy mầm là nguồn có giá trị về các hợp chất hoạt tính sinh học tự nhiên và chất chống oxy hóa. Tuy nhiên, hàm lượng các hợp chất này phụ thuộc rất lớn vào điều kiện xử lý hạt (thời gian ngâm hạt trước nẩy mầm) và chế độ nẩy mầm (nhiệt độ và thời gian), độ ẩm hạt, môi trường nẩy mầm sáng hay tối và độ ẩm tương đối của môi trường (El-Adawy \& ctv., 2003; Paucar-Menacho \& ctv., 2017). Vì thế, xác định điều kiện ngâm và ủ trong quá trình nẩy mầm hạt đậu xanh nhằm thu được các hàm lượng GABA và polyphenol cao nhất là điều quan trọng.

\section{Vật Liệu và Phương Pháp Nghiên Cứu}

\subsection{Nguyên liệu và hóa chất}

Đậu xanh (loại bỏ hạt vỡ, lép và các tạp chất) trồng tại tỉnh Tiền Giang được sử dụng cho các thí nghiệm. Sau đó, hạt được thu mua một lần và bảo quản trong ngăn mát tủ lạnh tránh hư hỏng; Chất chuẩn: GABA chuẩn, acid gallic chuẩn (Sigma Aldrich - Mỹ); Thuốc thử: Folin - Ciocalteur (Merk - Đức); Dung môi trích ly: ethanol, acetone, acid acetic (Xilong - Trung Quốc), allyl - L- glycine, triethylamine, methanol, phenyl isothiocyanate (Merk - Đức); Sodium hypochlorite $(\mathrm{NaOCl})$; Phenol $\left(\mathrm{C}_{6} \mathrm{H}_{5} \mathrm{OH}\right)$ (Xilong - Trung Quốc); Acid boric $\left(\mathrm{H}_{3} \mathrm{BO}_{3}\right)$, disodium tetraborate $\left(\mathrm{Na}_{2} \mathrm{~B}_{4} \mathrm{O}_{7} \cdot 10 \mathrm{H}_{2} \mathrm{O}\right)$ (Xilong Trung Quốc); Natri carbonate $\left(\mathrm{Na}_{2} \mathrm{CO}_{3}\right)$ (Xilong - Trung Quốc).

\subsection{Bố trí thí nghiệm}

Hai thí nghiệm được bố trí để đánh giá ảnh hưởng điều kiện ngâm và ủ đến hàm lượng GABA và polyphenol.

Thí nghiệm 1: Ảnh hưởng của nhiệt độ và thời gian ngâm đến hàm lượng $\mathrm{GABA}$ và polyphenol trong quá trình nẩy mầm. Thí nghiệm khảo sát thời gian và nhiệt độ ngâm được thiết kế theo kiểu 2 yếu tố hoàn toàn ngẫu nhiên, lặp lại 3 lần, bao gồm 3 chế độ thời gian ngâm $(6,8,10$ giờ) và 3 chế độ nhiệt độ ngâm $\left(30,35,40^{\circ} \mathrm{C}\right) \cdot 20 \mathrm{~g}$ hạt đậu xanh được rửa sạch và ngâm tỉ lệ $1: 5(\mathrm{w} / \mathrm{w})$ trong nước ở chế độ thời gian và nhiệt độ ngâm của các nghiệm thức. Sau các khoảng thời gian ngâm, hạt đậu xanh được ủ ở $30^{\circ} \mathrm{C} / 24$ giờ. Mầm đậu xanh được thu hoạch và bảo quản ở nhiệt độ $-18^{0} \mathrm{C}$ trong vòng 24 giờ để phân tích.

Thí nghiệm 2: Xác định ảnh hưởng của thời gian và nhiệt độ ủ lên hàm lượng GABA và polyphenol trong quá trình nẩy mầm. Thí nghiệm khảo sát thời gian và nhiệt độ ủ được thiết kế theo kiểu 2 yếu tố hoàn toàn ngẫu nhiên, lặp lại 3 lần, trong đó bao gồm 4 chế độ thời gian ủ $(12,24$, 36,48 giờ) và 3 chế độ nhiệt độ ủ $\left(30,35,40^{\circ} \mathrm{C}\right)$. 20 g hạt đậu xanh được rửa sạch và ngâm tỉ lệ 1:5 (w/w) trong nước ở chế độ thời gian và nhiệt độ ngâm ở thí nghiệm 1. Sau ngâm, hạt đậu xanh được ủ ở các khoảng thời gian và nhiệt độ khác nhau. Mầm đậu xanh được thu hoạch và bảo quản ở nhiệt độ $-18^{0} \mathrm{C}$ trong vòng 24 giờ để phân tích.

\subsection{Phương pháp phân tích các chỉ tiêu}

Phương pháp xác định hàm lượng GABA (Kitaoka \& Nakano, 1969; Watchararparpaiboon \& ctv., 2010).

Hàm lượng GABA được đo theo phương pháp đo quang. Mẫu được nghiền nhỏ và pha loãng bằng ethanol $70 \%$ theo tỷ lệ $1: 10(\mathrm{w} / \mathrm{w})$, khuấy trong 30 phút, sau đó ly tâm 2 lần ở nhiệt độ $4^{0} \mathrm{C}$ với tốc độ 10.000 (vòng/phút) trong thời gian 10 phút. Tiến hành bay hơi hết ethanol ở nhiệt độ $90^{\circ} \mathrm{C}$ trong 30 phút, pha loãng với nước cất và khuấy trong 15 phút, sau đó ly tâm ở $4^{0} \mathrm{C}$ với tốc độ 10000 (vòng/phút) trong 10 phút. Dịch sau khi ly tâm được sử dụng để phân tích GABA. Hút $600 \mu \mathrm{L}$ dung dịch vừa trích ly vào ống nghiệm rồi thêm $400 \mu \mathrm{L}$ hỗn hợp dung dịch đệm borate $0,4 \mathrm{M}$, thêm vào $2 \mathrm{~mL}$ thuốc thử phenol $6 \%$ vào ông nghiệm chứa mẫu vừa trích ly. Tiếp theo, cho thêm thuốc thử $\mathrm{NaOCl} 8 \%(2 \mathrm{~mL})$ vào rồi 
lắc mạnh trong 5 phút. Sau cùng, đun nóng hỗn hợp trên đến $70^{\circ} \mathrm{C}$ trong 10 phút rồi làm nguội mẫu đến nhiệt độ $30^{\circ} \mathrm{C}$. Tiến hành đo quang ở bước sóng $630 \mathrm{~nm}$. Kết quả GABA được tính theo hàm lượng chất khô dựa vào phương trình đường chuẩn: $\mathrm{y}=0,0254 \mathrm{x}+0,007$ với $\mathrm{R}^{2}=0,9953$.

Phương pháp xác định hàm lượng polyphenol tổng theo tác giả Złotek \& ctv. (2016).

Mẫu được nghiền nhỏ và pha với dung dịch trích ly gồm hỗn hợp $70 \%$ acetone, $0,5 \%$ acid acetic và $29,5 \%$ nước theo tỷ lệ 1: 20 rồi khuấy trong 2 giờ và giữ ngâm trong 12 giờ, ly tâm ở 3000 vòng trong 10 phút. Phần dịch sau khi trích ly được sử dụng để định lượng TPC. Hút $500 \mu \mathrm{L}$ mẫu trích ly thêm $2 \mathrm{~mL}$ nước cất, sau đó hút thêm $500 \mu \mathrm{L}$ thuốc thử Folin - Ciocalteu (tỷ lệ thuốc thử/nước: $1 / 10$ ) và $2 \mathrm{~mL} \mathrm{Na}_{2} \mathrm{CO}_{3} 7,0 \%$, lắc đều rồi để yên 8 phút ở nhiệt độ phòng. Giữ yên hỗn hợp trên trong 1 giờ ở nhiệt độ phòng. Đo độ hấp thụ bước sóng ở $765 \mathrm{~nm}$. Định lượng dựa vào đồ thị đường chuẩn của acid gallic: $\mathrm{y}=$ $0,0012 \mathrm{x}+0,0015$ với $\mathrm{R}^{2}=0,9999$. Kết quả được thể hiện bằng số mg tương đương acid gallic/g.

\subsection{Phương pháp xử lý số liệu}

Các dữ liệu được phân tích ANOVA bằng phần mềm Statgraphic và Excel.

\section{Kết Quả và Thảo Luận}

\section{1. Ảnh hưởng của nhiệt độ và thời gian ngâm}

Kết quả khảo sát ảnh hưởng của nhiệt độ và thời gian ngâm hạt đậu xanh đến hàm lượng GABA được trình bày qua Hình 1 . Kết quả phân tích thống kê cho thấy sự thay đổi hàm lượng GABA $(\mathrm{mg} / \mathrm{g})$ bị ảnh hưởng đáng kể bởi nhiệt độ và thời gian $(P<0,05)$, hàm lượng GABA cao nhất $(4,51 \mathrm{mg} / \mathrm{g})$ đạt được ở nhiệt độ ngâm $30^{\circ} \mathrm{C}$ trong 8 giờ.

Khi thời gian ngâm đạt mức 8 giờ ở nhiệt độ $30^{\circ} \mathrm{C}$ và khác biệt này có ý nghĩa với hàm lượng GABA ứng với các chế độ ngâm khác nhau. Qua Hình 1 cho thấy khi thời gian ngâm tăng từ 6 giờ lên 8 giờ thì hàm lượng GABA cũng có xu hướng tăng theo, tuy nhiên khi thời gian ngâm nhiều hơn 8 giờ thì xuất hiện sự suy giảm của hàm lượng GABA.

Ngâm đậu là giai đoạn cần thiết trong quá trình nẩy mầm hạt để làm tăng hàm lượng nước của hạt (ẩm độ tăng từ 11,2\% lên 60,6\%), thúc

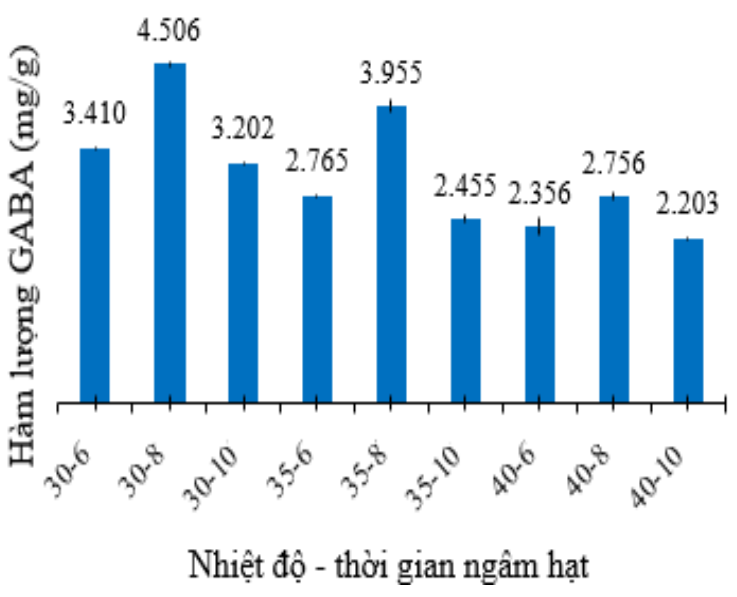

Hình 1. Ảnh hưởng của nhiệt độ ngâm $\left({ }^{0} \mathrm{C}\right)$ và thời gian ngâm (giờ) đến hàm lượng GABA của hạt đậu xanh nẩy mầm.

đẩy quá trình nẩy mầm xảy ra (Guo \& ctv., 2011). Giai đoạn này cũng rất quan trọng để kiểm soát sự phát triển của enzyme cần cho quá trình nẩy mầm. Tuy nhiên khi thời gian ngâm kéo dài, hàm lượng amino acid bên trong đậu xanh dễ dàng bị hòa tan trong nước, làm cho hàm lượng GABA suy giảm đáng kể. Ngoài ra, khi hạt đậu xanh được ngâm trong thời gian dài sẽ dẫn đến tình trạng thiếu oxy và ảnh hưởng không tốt đến sự nẩy mầm của hạt. Đồng thời nhiệt độ cũng là yếu tố kích thích sự nẩy mầm và sản sinh GABA. Kết quả nghiên cứu cho thấy nhiệt độ $30^{\circ} \mathrm{C}$ là nhiệt độ ngâm thích hợp cho quá trình tổng hợp GABA trong hạt đậu xanh.

Từ kết quả thí nghiệm trên, chế độ ngâm hạt đậu xanh để sinh GABA tối ưu là ở nhiệt độ $30 \circ \mathrm{C}$ trong khoảng thời gian là 8 giờ. Chế độ ngâm này sẽ được chọn làm yếu tố cố định cho các thí nghiệm tiếp theo về sự ảnh hưởng của chế độ nẩy mầm lên hàm lượng GABA. Theo Huang \& ctv. (2014), hàm lượng của các hợp chất phenolic trong hạt đậu xanh cũng có sự thay đổi rõ rệt sau quá trình nẩy mầm. Quá trình nẩy mầm có hiệu quả trong việc phá vỡ các đại phân tử và làm giàu chất dinh dưỡng có trong đậu xanh. Trong đó, nhiệt độ ngâm và thời gian ngâm có ảnh hưởng rõ rệt đến hàm lượng polyphenol với mức ý nghĩa $P<0,05$.

Theo kết quả Hình 2, hàm lượng TPC cao nhất $(1,25 \mathrm{mg} / \mathrm{g})$ đạt được tại chế độ ngâm có nhiệt độ là $35^{\circ} \mathrm{C}$ trong vòng 8 giờ và có sự khác biệt có ý nghĩa so với các nghiệm thức khác.

Qua Hình 2 cho thấy, khi thời gian và nhiệt 


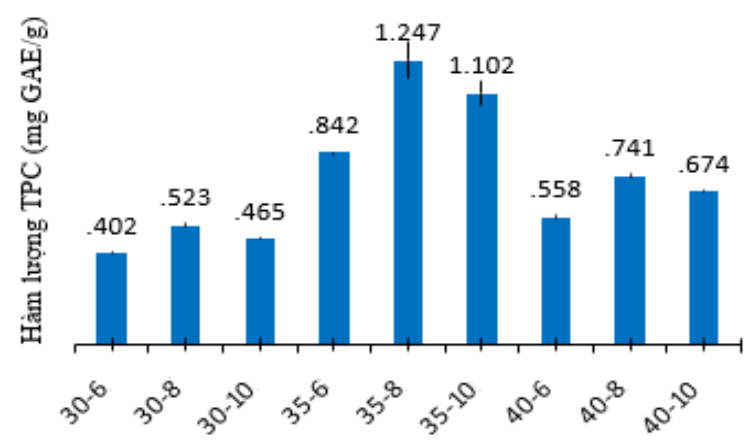

Nhiệt độ - thời gian ngâm hạt

Hình 2. Ảnh hưởng của nhiệt độ ngâm $\left({ }^{0} \mathrm{C}\right)$ và thời gian ngâm (giờ) lên hàm lượng TPC của hạt đậu xanh.

độ tăng thì hàm lượng polyphenol cũng có chiều hướng gia tăng. Tuy nhiên, khi nhiệt độ và thời gian ngâm đạt tới một ngưỡng nhất định thì hàm lượng TPC sẽ có chiều hướng giảm. Theo Tiansawang \& ctv. (2016), khoảng thời gian ngâm hạt tối ưu cho hàm lượng polyphenol cao nhất là 6 - 8 giờ, điều này trùng khớp với kết quả về thời gian ngâm hạt trong nghiên cứu này. Các nghiên cứu trước đây chỉ ra rằng, lượng nước hạt hấp thụ và thời gian ngâm có ảnh hưởng lớn đế khả năng sinh tổng hợp polyphenol có trong hạt (Akillioglu \& Karakaya, 2010). Trước quá trình nẩy mầm, phần lớn hàm lượng polyphenol tập trung trong lớp vỏ ngoài của hạt đậu xanh. Qua Hình 2 cho thấy, khi giá trị của thời gian và nhiệt độ tăng thì hàm lượng polyphenol cũng có chiều hướng gia tăng. Tuy nhiên, khi nhiệt độ và thời gian ngâm đạt tới một ngưỡng nhất định thì giá trị của hàm lượng TPC sẽ có chiều hướng giảm. Điều này được gải thích là do khi ngâm hạt trong một khoảng thời gian dài, lượng nước hạt hấp thụ được sẽ bị dư thừa, điều này đồng thời dẫn đến sự mất cân bằng oxy làm giảm khả năng nẩy mầm của hạt. Như vậy, đối với hàm lượng polyphenol, chế độ ngâm hạt tối ưu là ở nhiệt độ ngâm $35^{\circ} \mathrm{C}$ trong khoảng thời gian ngâm là 8 giờ. Các thông số này sẽ được bố trí cố định cho các thí nghiệm tiếp theo liên quan đến việc khảo sát ảnh hưởng của chế độ ngâm lên hàm lượng TPC.

\section{2. Ảnh hưởng của nhiệt độ và thời gian ủ}

Sự ảnh hưởng của nhiệt độ và thời gian ủ đến hàm lượng GABA $(\mathrm{mg} / \mathrm{g})$ được thể hiện trong Hình 3.
Kết quả phân thích thống kê cho thấy nhiệt độ và thời gian ủ có ảnh hưởng đáng kể đến quá trình sinh tổng hợp GABA $(\mathrm{mg} / \mathrm{g})$ với mức ý nghĩa $P$ $<0,05$. Chế độ nẩy mầm ở nhiệt độ $35^{0} \mathrm{C}$ trong 24 giờ đã cho hàm lượng GABA là cao nhất, đạt 4,46 mg/g và có sự khác biệt rõ ràng với các chế độ còn lại.

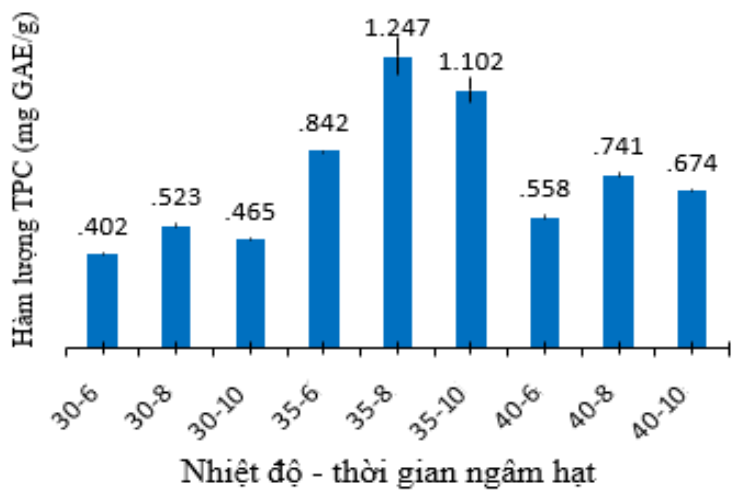

Hình 3. Ảnh hưởng nhiệt độ và thời gian ủ đến hàm lượng GABA.

Về yếu tố nhiệt độ, hàm lượng GABA tăng khi nhiệt độ nẩy mầm tăng từ $30^{\circ} \mathrm{C}$ đến $35^{\circ} \mathrm{C}$. Tuy nhiên, khi nhiệt độ nẩy mầm tiếp tục tăng thì hàm lượng GABA cũng có dấu hiệu suy giảm. Dựa trên các nghiên cứu của Hussain \& Uddin (2012) cho thấy hạt đậu xanh sau khi ngâm được ủ kín trong môi trường có nhiệt độ là $33,4^{0} \mathrm{C}$ làm cải thiện tốt hơn thành phần dinh dưỡng của hạt. Trong khi đó, Komatsuzaki \& ctv. (2007) với đối tượng nghiên cứu là hạt gạo lứt lại cho ra nhiệt độ ươm mầm tối ưu là $35^{\circ} \mathrm{C}$, để thu được hàm lượng GABA cao nhất.

Về yếu tố thời gian, có thể dễ dàng nhận thấy, thời gian nẩy mầm trong vòng 12 giờ luôn cho kết quả về hàm lượng GABA thấp nhất. Điều này là do trong khoảng thời gian 12 giờ, chu trình sinh tổng hợp GABA chưa diễn ra triệt để, quá trình chuyển hóa glutamic acid thành GABA do enzyme glutamic acid decacboxylase chưa đạt hiệu suất cao nhất. Theo Chung \& ctv. (2009), trong quá trình nẩy mầm, các enzyme sẽ được kích hoạt, làm thoái hóa các hợp chất chính như carbonhydrate và protein, tạo nên các hợp chất như GABA, các chất xơ tiêu hóa được và vitamin. Cho nên, khoảng thời gian ủ cần đủ dài để quá trình này xảy ra triệt để. Tuy nhiên, hàm lượng GABA tăng lên khi thời gian ủ tăng sau đó lại sụt giảm khi thời gian ươm mầm tiếp tục kéo dài hơn. Nguyên nhân là do sự kéo dài thời gian nẩy mầm 
làm cho $\mathrm{pH}$ của khối hạt sẽ thay đổi, ức chế hoạt động của enzyme $\mathrm{GAD}$ và kích thích sự hoạt động của enzyme GABA-T, enzyme thủy phân GABA. Ngoài ra, do quá trình ủ diễn ra ở điều kiện yếm khí nên việc kéo dài thời gian nẩy mầm sẽ làm hạt mùi ôi khó chịu, thâm nâu và khó sử dụng trong các thành phẩm ứng dụng sau này. Việc so sánh kết quả thí nghiệm với một số nghiên cứu khác cũng cho thấy một vài sự trùng khớp cũng như khác biệt. Cụ thể, trong nghiên cứu được tiến hành bởi Karladee \& Suriyong (2012) trên đối tượng là 21 giống lúa cho nẩy mầm của Thái Lan cho thấy hàm lượng GABA đạt ngưỡng cao nhất với thời gian ủ là 24 giờ, sau đó giảm dần khi tăng thời gian nẩy mầm. Điều này có phần tương thích với kết quả được chứng minh trong nghiên cứu này. Tuy nhiên, trong nghiên cứu của Banchuen \& ctv. (2009), trên hạt gạo lứt nẩy mầm thì thời gian ủ tối ưu lại là 36 giờ. Sự khác biệt về kết quả của thời gian và nhiệt độ ủ giữa nghiên cứu này và các nghiên cứu khác được cho là do sự khác biệt về đối tượng nghiên cứu, điều kiện, môi trường và phương pháp nghiên cứu có sự khác biệt. Như vậy, kết quả từ nghiên cứu của đề tài này cho thấy chế độ nẩy mầm tốt nhất cho quá trình sinh tổng hợp GABA trong đậu xanh là ở nhiệt độ $35^{\circ} \mathrm{C}$ trong thời gian 24 giờ.

Kết quả phân tích thống kê cho thấy nhiệt độ và thời gian ủ ảnh hưởng có ý nghĩa đến quá trình sinh tổng hợp TPC (mg GAE/g) với mức ý nghĩa $P<0,05$. Theo Hình 4 , chế độ nẩy mầm ở nhiệt độ $35^{\circ} \mathrm{C}$ trong vòng 24 giờ cho kết quả về hàm lượng TPC cao nhất (1,30 mg GAEg).

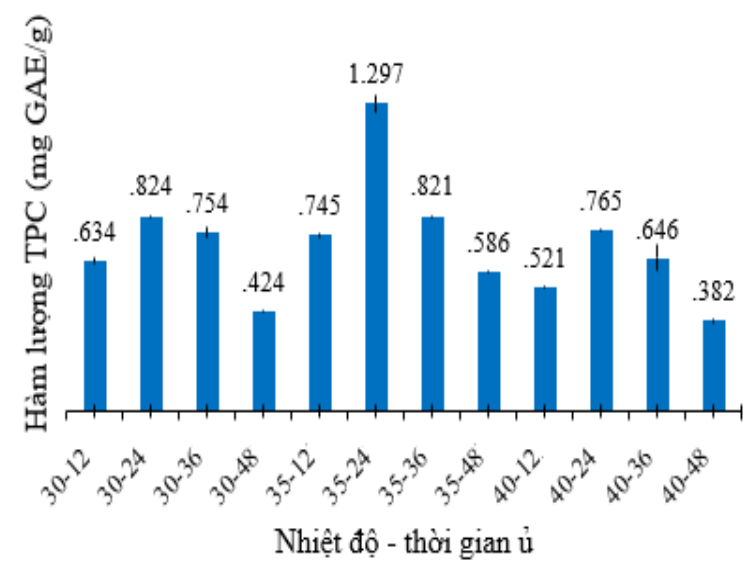

Hình 4. Ảnh hưởng của nhiệt độ $\left({ }^{0} \mathrm{C}\right)$ và thời gian ủ (giờ) đến hàm lượng polyphenol.

Về nhiệt độ ủ, hàm lượng polyphenol tổng tăng khi nhiệt độ nẩy mầm tăng từ khoảng $30^{\circ} \mathrm{C}$ lên $35^{0} \mathrm{C}$, tuy nhiên lại giảm một cách đáng chú ý khi nhiệt độ đạt mức $40^{\circ} \mathrm{C}$. Theo Hussain \& Uddin (2012), nhiệt độ nẩy mầm tối ưu của lúa mì là từ $30^{\circ} \mathrm{C}$ đến $37^{0} \mathrm{C}$. Trong khoảng nhiệt độ này, giá trị dinh dưỡng của hạt sẽ tăng đáng kể. Khi nhiệt độ tiếp tục gia tăng, quá trình ủ của hạt sẽ bị ức chế, do đó, quá trình phân giải các carbonhydrate và protein thành các sản phẩm mới cũng bị suy giảm, dẫn theo sự suy giảm về hàm lượng polyphenol.

Về thời gian nẩy mầm, kết quả cho thấy 24 giờ là thời gian nẩy mầm tối ưu để sản sinh polyphenol trong hạt. Theo nghiên cứu của Tiansawang \& ctv. (2016), thời gian ủ tối ưu cho hàm lượng TPC cao nhất là 48 giờ trên các loại hạt khác nhau, trong đó có đậu xanh. Trong khi đó, Fernandez-Orozco \& ctv. (2008) công bố rằng hàm lượng polyphenol gia tăng cao nhất là từ 2 đến 7 ngày nẩy mầm hạt đậu xanh. Tuy nhiên, Wongsiri \& ctv. (2015) đã công bố TPC của hạt đậu xanh nẩy mầm tăng lên cao nhất là sau 24 giờ cho lên mầm, cao gấp 4 lần so với hạt tươi. Nguyên nhân là do sau khi nẩy mầm, chất dinh dưỡng trong hạt tăng lên, là điều kiện cực thuận lợi cho các hệ vi sinh vật thâm nhập và phát triển; đồng thời, cũng là thời điểm hạt chịu sự tấn công mạnh của côn trùng từ môi trường bên ngoài. Điều này là nguyên nhân dẫn đến sự tổng hợp các hợp chất phenolic để kháng lại vi khuẩn và các côn trùng gây hại. Như vậy, chế độ ủ hợp lý để hàm lượng polyphenol cao nhất là nhiệt độ $35^{0} \mathrm{C}$ trong 24 giờ.

\section{Kết Luận}

Thời gian ngâm hạt và nhiệt độ ngâm hạt ảnh hưởng đến hàm lượng GABA và polyphenol có trong đậu xanh. Trong đó, nhiệt độ ngâm tối ưu là $30^{\circ} \mathrm{C} / 8$ giờ, cho hàm lượng $\mathrm{GABA}$ là cao nhất, với $4,51 \mathrm{mg} / \mathrm{g}$ và $35^{\circ} \mathrm{C} / 8$ giờ cho hàm lượng $\mathrm{TPC}$ là cao nhất, với $1,25 \mathrm{mg} \mathrm{GAE} / \mathrm{g}$.

Thời gian nẩy mầm và nhiệt độ ủ cũng có ảnh hưởng lên hàm lượng GABA và polyphenol thu được sau nẩy mầm. Trong đó, hàm lượng GABA đạt tối ưu $(4,46 \mathrm{mg} / \mathrm{g})$ trong khoảng thời gian là 24 giờ trong khoảng nhiệt dộ là $35^{0} \mathrm{C}$. Tương tự, hàm lượng $\mathrm{TPC}$ đạt mức độ cao nhất $(1,30 \mathrm{mg}$ $\mathrm{GAE} / \mathrm{g})$ khi nhiệt độ ở $35^{0} \mathrm{C}$ trong vòng 24 giờ ủ. 


\section{Tài Liệu Tham Khảo (References)}

Ajila, C. M., Brar, S. K., Verma, M., Tyagi, R. D., Godbout. S., \& Valéro, J. R. (2011). Extraction and analysis of polyphenols: Recent trends. Critical Reviews in Biotechnology 31(3), 227-249.

Akillioglu, H. G., \& Karakaya, S. (2010). Changes in total phenols, total flavonoids, and antioxidant activities of common beans and pinto beans after soaking, cooking, and in vitro digestion process. Food Science and Biotechnology 19(3), 633-639.

Banchuen, J., Thammarutwasik, P., \& Ooraikul, B. (2009). Effect of germinating processes on bioactive component of Sangyod Muang Phatthalung rice. Thai Journal of Agricultural Science 42(4), 191-199.

Chung, H. J., Jang, H.C., Cho, H. Y., \& Lim, S. T. (2009). Effects of steeping and anaerobic treatment on GABA ( $\gamma$-aminobutyric acid) content in germinated waxy hull-less barley. LWT - Food Science and Technology 42(10), 1712-1716.

El-Adawy, T. A., Rahma, E. H., El-Bedawey, A. A., \& ElBeltagy, A. E. (2003). Nutritional potential and functional properties of germinated mung bean, pea and lentil seeds. Plant Foods for Human Nutrition 58(3), $1-13$.

Fernandez-Orozco, R., Frias, J., Zielinski, H., Piskula, M. K., Kozlowska, H., \& Vidal-Valverde, C. (2008). Kinetic study of the antioxidant compounds and antioxidant capacity during germination of Vigna radiata $\mathrm{cv}$. emmerald, Glycine max cv. jutro and Glycine max cv. merit. Food Chemistry 111(3), 622-630.

Guo, Y., Chen, H., Song, Y., \& Gu, Z. (2011). Effects of soaking and aeration treatment on $\gamma$-aminobutyric acid accumulation in germinated soybean (Glycine max L.) European Food Research and Technology $232(5), 787-795$.

Huang, X., Cai, W., \& Xu, B. (2014). Kinetic changes of nutrients and antioxidant capacities of germinated soybean (Glycine max l.) and mung bean (Vigna radiata 1.) with germination time. Food Chemistry 143, 268-276.

Hussain, I., \& Uddin, M. B. (2012). Optimization of germination conditions for germinated wheat flour by response surface methodology. African Journal of Food Science and Technology 3(1), 16-22.

Kanatt, S. R., Arjun, K., \& Sharma, A. (2011). Antioxidant and antimicrobial activity of legume hulls. Food Research International 44(10), 3182-3187.
Karladee, D., \& Suriyong, S. (2012). $\gamma$-Aminobutyric acid (GABA) content in different varieties of brown rice during germination. Science Asia 38(1), 13-17.

Kitaoka, S., \& Nakano, Y. (1969). Colorimetric determination of w-amino acids. The Journal of Biochemistry 66(1), 87-94.

Komatsuzaki, N., Tsukahara, K., Toyoshima, H., Suzuki, T., Shimizu, N., \& Kimura, T. (2007). Effect of soaking and gaseous treatment on GABA content in germinated brown rice. Journal of Food Engineering 78(2), 556-560.

Paucar-Menacho, L. M., Peñas, E., Dueñas, M., Frias, J., \& Martínez-Villaluenga, C. (2017). Optimizing germination conditions to enhance the accumulation of bioactive compounds and the antioxidant activity of kiwicha (Amaranthus caudatus) using response surface methodology. LWT - Food Science and Technology 76, 245-252.

Randhir, R., Lin, Y. T., \& Shetty, K. (2004). Stimulation of phenolics, antioxidant and antimicrobial activites in dark germinated mung bean sprouts in response to peptide and phytochemical elicitors. Process Biochemistry 39(3), 637-646.

Song, H. Y., \& Yu, R. C. (2018). Optimization of culture conditions for gamma-aminobutyric acid production in fermented adzuki bean milk. Journal of Food and Drug Analysis 26(1), 74-81.

Tiansawang, K., Luangpituksa, P., Varanyanond, W., \& Hansawasdi, C. (2016). GABA ( $\gamma$-aminobutyric acid) production, antioxidant activity in some germinated dietary seeds and the effect of cooking on their GABA content. Food Science and Technology 36(2), 313-321.

Watchararparpaiboon, W., Laohakunjit, N., \& Kerdchoechuen, O. (2010). An improved process for high quality and nutrition of brown rice production. Food Science and Technology International 16(2), 147-158.

Wongsiri, S., Ohshima, T., \& Duangmal, K. (2015). Chemical composition, amino acid profile and antioxidant activities of germinated mung beans (Vigna radiata). Journal of Food Processing and Preservation 39(6), 1956-1964.

Złotek, U., Mikulska, S., Nagajek, M., \& Świeca, M. (2016). The effect of different solvents and number of extraction steps on the polyphenol content and antioxidant capacity of basil leaves (Ocimum basilicum L.) extracts. Saudi Journal of Biological Sciences 23(5), 628-633. 